\title{
¿Podrías decirme, por favor, qué camino he de tomar para salir de aquí?
}

Would you tell me, please, which way I ought to go from here?

Javier Pallarés Neila ${ }^{\text {a }}$

${ }^{a}$ Licenciado en derecho, abogado y graduado en psicología.

Correspondencia: Javier Pallarés Neila (javipane@gmail.com)

Recibido: 15/07/2013; aceptado: 23/09/2013

RESUMEN: Después de las sentencias del Tribunal constitucional de diciembre del 2010 y de julio del 2012, el legislador español se encuentra obligado a reformar la regulación del denominado "internamiento involuntario por razón de trastorno psíquico”. En este artículo se promueve que dicha reforma parta como punto de referencia de la noción clínica del tratamiento médico, en conformidad con las normas y principios internacionales propugnados desde la Organización Mundial de la Salud, prescindiendo de la utilización del término de internamiento involuntario, ya que atrae una connotaciones prejuiciosas que en nada ayudan a romper con el estigma que padecen las personas con trastorno mental y tiene además unas repercusiones jurídicas, penales y constitucionales, de obligado cumplimiento. Se examinan, asimismo, las normas del ordenamiento jurídico español, sobre el tratamiento en salud mental, en las que la reforma puede sustentarse sin necesidad de crear una legislación especial: Ley General de Sanidad, El Convenio para la protección de los Derechos Humanos y la Dignidad del Ser Humano con respecto a las aplicaciones de la Biología y la Medicina y Ley básica reguladora de la autonomía del paciente y de derechos y obligaciones en materia de información y documentación clínica y se proponen las bases o principios desde los que podría acometerse la modificación en estas materia.

PALABRAS CLAVE: Internamiento involuntario; artículo 763 de la Ley de Enjuiciamiento Civil; Tratamiento involuntario o forzoso; derechos fundamentales.
ABSTRACT:Following the judgments of the Constitutional Court in December 2010 and July 2012, the Spanish legislator is obliged to reform the regulation of the so-called "involuntary confinement on grounds of mental disorder". This article promotes that this reform uses the clinical notion of medical treatment as a reference point, in accordance with the international rules and principles advocated by the World Health Organization. It is supported that the term involuntary confinement is no longer used since it draws prejudicial connotations that do nothing to help break the stigma experienced by people with mental disorder and it has additional legal, criminal and constitutional mandatory implications. They are examined the rules of the Spanish legal system on mental health treatment, which can sustain the reform without creating special legislation: General Health Law, the Convention for the Protection of Human Rights and dignity of the Human Being with regard to the Application of Biology and Medicine and Basic Law regulating patient autonomy and rights and obligations of information and clinical documentation and it is proposed the bases or principles from which the modification could be undertaken in these matters. KEY WORDS: Involuntary commitment; article 763 Ley de Enjuiciamiento Civil (Rules of civil procedure); Involuntary treatment order; Human rights.

\section{Introducción.-}

- ¿Podrías decirme, por favor, qué camino he de tomar para salir de aquí?

-Depende mucho del punto adonde quieras ir- contestó el Gato.

-Me da casi igual dónde- dijo Alicia.

-Entonces no importa qué camino sigas- dijo el Gato”. 
Si bien nunca ha sido un tema pacífico, en los últimos años se ha venido suscitando un vivo debate en nuestra sociedad acerca de la regulación del denominado "internamiento involuntario por razón de trastorno psíquico".

Comenzó hace ya varios años con la propuesta de introducir en el 763 de la Ley de Enjuiciamiento Civil (LEC) un nuevo párrafo, en el que se admitiera expresamente la posibilidad de incluir un tratamiento involuntario. Esta modificación, originariamente defendida por la Confederación española de agrupaciones de familiares y personas con enfermedad mental (FEAFES), llegó a ser tramitada como Proposición de Ley por el Grupo parlamentario catalán Convergència i Unió quien presentó una proposición de ley en el Congreso de los Diputados (1). El tema sin embargo se disolvió entre las aguas de la nueva legislatura.

La Asociación española de neuropsiquiatría se mostró contraria al tratamiento involuntario (2), "por tratarse de una regulación legislativa específica para las personas que padecen trastornos psíquicos y no existir suficiente nivel de evidencia sobre su eficacia como para recomendar su aplicación", insistiendo en la necesidad de desarrollar completamente el modelo comunitario previsto en la Ley General de Sanidad.

Pero si parecía que el debate quedaba establecido de forma maniquea en torno a estar "a favor" o "en contra" del tratamiento involuntario, desde hace meses la polémica se ha visto desplazada hacia la propia medida del internamiento involuntario.

Así, de una parte, FEAFES ha modificado su postura pasando de la promoción del tratamiento involuntario, al rechazo primero y, después, de forma más sosegada, a la crítica del propio acto del internamiento, en favor de medidas de atención comunitaria.

Pero la radicalización de las posturas tendría su máximo exponente en el Comité Español de Representantes de Personas con Discapacidad (CERMI), que tras la entrada en vigor en España el 3 de mayo de 2008, del instrumento de Ratificación de la Convención sobre los derechos de las personas con discapacidad, hecho en Nueva York el 13 de diciembre de 2006, asumió sin cortapisa alguna los informes del Relator Especial de la ONU (3) sobre la tortura, que exhortaba a todos los estados a:

“a) Examinar el marco contra la tortura en relación con las personas con discapacidad y ajustarlo a la Convención sobre los derechos de las personas con discapacidad, de forma que sea una orientación autorizada sobre los derechos de estas personas en el contexto de la atención de la salud.

b) Imponer una prohibición absoluta de todas las intervenciones médicas forzadas y no consentidas en los casos de personas con discapacidad, incluida la psicocirugía, la terapia de electrochoque, la administración de medicamentos psicotrópicos como los neurolépticos, la inmovilización y el régimen de aislamiento, 
ORIGINALES Y REVISIONES

tanto a largo como a corto plazo, cuando no exista consentimiento. La obligación de poner fin a las intervenciones psiquiátricas forzadas basadas únicamente en motivos de discapacidad es de inmediata aplicación y la escasez de recursos financieros no podrá justificar el aplazamiento de dicha aplicación.

c) Sustituir el tratamiento y el internamiento forzosos por servicios en la comunidad. Esos servicios deben satisfacer las necesidades expresadas por las personas con discapacidad y respetar la autonomía, opciones, dignidad y privacidad de la persona, haciendo hincapié en otras opciones distintas al modelo médico de salud mental, incluidos el apoyo entre pares, la concienciación y la capacitación del personal de atención de salud mental y el personal encargado de hacer cumplir la ley y otros colectivos.

d) Revisar las disposiciones jurídicas que permiten la privación de libertad por razones de salud mental o en instalaciones de salud mental, y de cualesquiera intervenciones o tratamientos coercitivos en entornos de salud mental sin el consentimiento libre e informado de la persona concernida. Deben abolirse las normas que autorizan el internamiento en una institución de las personas con discapacidad en razón de esta y sin su consentimiento libre e informado."

Por si fuera poco, este panorama no ha hecho más que empeorar a consecuencia de dos resoluciones de nuestro Tribunal Constitucional: la primera del Pleno del Tribunal Constitucional, 132/2010, de 2 de Diciembre (4) de finales del 2010, advirtiendo de la inconstitucional del artículo 763 de la Ley de Enjuiciamiento Civil por vulneración de lo dispuesto en el artículo 81 de la Constitución y, la segunda, de mayor enjundia, sobre el desarrollo de la medida en referencia expresa a la modalidad de internamiento urgente.

El contenido de la primera sentencia no es que fuera baladí. Declaraba, nada menos, la inconstitucionalidad de dicha norma por no respetar el rango formal que merecía, ya que afecta al derecho fundamental de la libertad individual del artículo 17 de la Constitución. La regulación a través de Ley orgánica no es asunto meramente formal de distribución de competencias o rango normativo, sino que incide directamente en el sistema de garantías de los derechos fundamentales, exigiendo una mayoría cualificada para su aprobación: mayoría absoluta del Congreso. Sin embargo, no va más allá y no declara su nulidad "al no haberse cuestionado su contenido material y atendiendo al vacío no deseable que de otro modo se hubiera creado dentro del ordenamiento..."

En cualquier caso esto significa, que el grupo político mayoritario en el año 1983, cuando se reformó el artículo 211 del Código Civil; el grupo mayoritario del año 1996, fecha en la que se volvió a modificar; su homólogo, del año 2000 , cuando se promulgó la Ley de Enjuiciamiento Civil introduciéndose el artículo 763 , tendrían que haber buscando un consenso mucho mayor que el obtenido para legislar o modificar el sistema de internamiento involuntario. Desgraciada- 
mente se utilizó el camino más rápido, el menos garantista, con el resultado de la aplicación por jueces y tribunales, desde hace más de 30 años, de una norma inconstitucional.

Pese a ello, resulta si cabe de mayor importancia la sentencia de la Sala Segunda del Tribunal Constitucional 141/2012 de 2 julio, (5) ya que al incidir sobre el desarrollo de la medida y las garantías que deben adoptarse al respecto, pone en tela de juicio el acto mismo y, claro está, la actuación por parte de sus principales actores (secundarios): jueces, forenses, secretarios judiciales, abogados, psiquiatras y unidades psiquiátricas. Es más, si nadie pone remedio, esta sentencia informará exclusivamente la esperada actividad del legislador, en detrimento de otras mejoras que quizá sea oportuno introducir.

Veamos más detalladamente cuáles deben ser las características de la intervención de cada uno de estos actores secundarios, en una medida de internamiento involuntario urgente de conformidad con la citada doctrina constitucional:

Por una parte, los servicios de urgencia o las unidades de psiquiatría de los hospitales generales, deberán disponer de un protocolo de intervención en el que, al menos, se recoja lo siguiente:

- Ofrecer información comprensible al paciente sobre el internamiento y sus causas.

- Si se trata de una persona con capacidad de obrar limitada en el área de la salud, también se deberá informar a sus padres, en caso de tener la patria potestad prorrogada o rehabilitada, o a su tutor o a su curador, según los casos.

- Antes de las 72 horas del ingreso, deberá quedar redactado un informe donde quede plasmado el juicio médico, para su posterior control judicial.

- Deben comunicar al Juez competente, el hecho del internamiento y los motivos que lo justificaron. Sin dilación alguna y en todo caso en un plazo máximo de 24 horas, plazo que empieza a contar "desde el momento en que se produce materialmente el ingreso del afectado en el interior del recinto y contra su voluntad..."

- Posible solicitud de habeas corpus, tanto por la persona ingresada, como por parte de sus representantes o sus familiares, con la finalidad de recabar la tutela judicial inmediata.

Por otra, el órgano jurisdiccional competente tiene que cumplir con los siguientes requisitos:

- Con el plazo de 72 horas siguientes a la comunicación, que ya le era exigible conforme a lo dispuesto en el artículo 763 de la Ley de Enjuiciamiento Civil: 
ORIGINALES Y REVISIONES

“... La autorización será previa a dicho internamiento, salvo que razones de urgencia hicieren necesaria la inmediata adopción de la medida. En este caso, el responsable del centro en que se hubiere producido el internamiento deberá dar cuenta de éste al tribunal competente lo antes posible $y$, en todo caso, dentro del plazo de veinticuatro horas, a los efectos de que se proceda a la preceptiva ratificación de dicha medida, que deberá efectuarse en el plazo máximo de setenta y dos horas desde que el internamiento llegue a conocimiento del tribunal"

Pero ahora, con la expresa advertencia constitucional de que “... no puede mantenerse el confinamiento de la persona si a su expiración no se ha ratificado la medida, ni cabe aducir dificultades logísticas o excesiva carga de trabajo del órgano judicial para justificar su demora, ni puede considerarse convalidado el incumplimiento porque más tarde se dicte el Auto y éste resulte confirmatorio".

- Asimismo, deberá practicar en el acto todas las pruebas que se consideren oportunas y, de forma obligatoria, dos: examen personal por parte del juez y reconocimiento pericial por un médico designado por él. Estas pruebas también se venía practicando, pero de nuevo el constitucional pone el acento en el cómo, al manifestar expresamente "Que tanto el informe del hospital como también el del médico forense, recomendaran en un texto pre-impreso que continuara el internamiento, sin una concreta argumentación acerca de la necesidad y proporcionalidad de la medida, esto es, sin explicar por qué no hubiera bastado con un tratamiento ambulatorio para tratar el referido trastorno, como al parecer ya venía sucediendo con el recurrente, hace indebida su asunción acrítica por el Juzgado, quien ante ese vacío debió solicitar como mínimo aclaraciones o ampliación de su informe al médico forense, fuese para dar por ciertas aquellas notas de necesidad y proporcionalidad, fuese para no ratificar la medida caso de no obtener una opinión científica convincente. No habiéndolo hecho así, no cabe considerar, ni razonable ni dotada de la debida motivación reforzada, su decisión”.

- También es obligación del juzgado informar a la persona (o a su representante) acerca de su situación material y procesal, "lo que implica a su vez el derecho del afectado (o su representante en su nombre) a ser oído personalmente dentro del procedimiento".

- Y, por último, el juez debe informarle de su derecho a designar abogado que le asista, así como su derecho a la práctica de pruebas. Y, una vez más, no se trata de una mera posibilidad sometida al libre arbitrio del paciente, sino que el órgano jurisdiccional “... tome la iniciativa en la información, no presuponer su conocimiento por parte del afectado... ni tampoco dar por cubierta esa defensa con la presencia del Ministerio Fiscal el cual actúa en 
defensa de la legalidad y no como defensor judicial del interno, quien ha de tener por tanto siempre su propia voz y defensa dentro del procedimiento"

Por supuesto, de todo ello y bajo la fe pública procesal del Secretario Judicial, se deberá dejar constancia escrita; es decir se deberá extender acta de forma análoga a la que se practica la diligencia de información de derechos en cualquier centro de detención español.

Por último, la Consejería de Justicia, los Colegios de Abogados o la Comisiones de justicia gratuita de las respectivas Comunidades Autónomas, deberían poner en marcha un turno de oficio especial para cubrir estas asistencias a pacientes internados involuntariamente, cuando sea su deseo designar un letrado de oficio que les asista en este procedimiento, también en modo similar a lo que ocurre en la justicia penal ya que como en ésta, los servicios de urgencia funcionan las 24 horas.

El panorama, como vemos es complejo y supone una carga administrativa y la disponibilidad de recursos personales y materiales cuya consecución es difícil de conseguir en el momento actual, en el que precisamente predomina la restricción de ambos.

Materializando esos "considerandos" o "fundamentos jurídicos" en la actividad diaria del juzgado en cuyo partido judicial se encuentre algún recurso, público o privado, en cuya planta de psiquiatría existan personas internadas involuntariamente, deberán desplazarse sin excusa alguna, juez, secretario judicial y forense todos los martes y todos los viernes del año. Temporalmente no existe otra alternativa para cumplir el plazo de 72 horas del artículo 763.

El cumplimiento de esta exigencia, en un juzgado especializado en incapacidades y tutelas, puede ser posible pero resulta difícil de imaginar su organización desde uno de los tantos juzgados de $1^{\mathrm{a}}$ instancia o lo que es peor de $1^{\mathrm{a}}$ instancia e instrucción, que son los mayoritarios en el territorio español.

En cualquier caso, ni estas ni cualesquiera otras cuestiones similares empece tener que adoptar dichas exigencias so riego de incurrir en una conducta ilícita; así lo considera el Tribunal Constitucional y así lo considera quien suscribe, como veremos a continuación.

De las consideraciones semánticas y sus implicaciones legales

La pregunta del personaje de Lewis Caroll nos sirve para enmarcar la tesis que se intenta transmitir en este artículo: la sociedad española actual, 35 años después de la Constitución, no puede permitirse no saber dónde ir. En esta materia sólo puede existir una meta, la protección de los derechos de las personas con discapacidad. Pero además, no basta con declaraciones programáticas, ya que como advertía 
ORIGINALES Y REVISIONES

Bobbio el grave problema actual de nuestro tiempo, en lo relativo a los derechos del hombre es de su protección y no el de su fundamentación; el camino también es importante.

Para el diccionario de la Real Academia Española, internar es "disponer o realizar el ingreso de alguien en un establecimiento, como un hospital, una clínica, una prisión, etc".

Si bien en la definición no se entra a valorar el aspecto subjetivo o la intencionalidad del sujeto, un examen más detallado nos muestra que ya en el académico se encontraba la idea de que el ingreso puede realizarlo el propio sujeto, por sí, o acordarse por otro, como lo demuestra la utilización de los verbos "disponer o realizar".

De esta forma, el verbo internar podría fácilmente conjugarse con el de acceder; es decir, "entrar en un lugar o pasar a él", o como detener, en su acepción de "privación provisional de la libertad, ordenada por una autoridad competente".

De éstas, nos interesa analizar la segunda acepción, en la que la persona no es sujeto activo, sino pasivo; es decir cuando alguien dispone el ingreso de otra persona sin contar con su consentimiento o en contra de su voluntad.

Planteado el objeto, debemos enmarcarlo en el estado social y democrático del derecho que reconoce el artículo 1 del texto constitucional y partir así de dos premisas fundamentales:

La primera, en pleno respeto a lo dispuesto en el artículo 10 de la Constitución, conforme al cual:

"1.- La dignidad de la persona, los derechos inviolables que le son inherentes, el libre desarrollo de la personalidad, el respeto a la Ley y a los derechos de los demás son fundamento del orden político y de la paz social”.

2. Las normas relativas a los derechos fundamentales y a las libertades que la Constitución reconoce se interpretarán de conformidad con la Declaración Universal de Derechos Humanos y los Tratados y acuerdos internacionales sobre las mismas materias ratificados por España".

La segunda, por lo dispuesto en el artículo 17 del mismo texto:

1. "Toda persona tiene derecho a la libertad y a la seguridad. Nadie puede ser privado de su libertad, sino con la observancia de lo establecido en este artículo y en los casos y en la forma previstos en la Ley"

2. La detención preventiva no podrá durar más del tiempo estrictamente necesario para la realización de las averiguaciones tendentes al esclarecimiento de los hechos, y, en todo caso, en el plazo máximo de setenta y dos horas, el detenido deberá ser puesto en libertad o a disposición de la autoridad judicial".

Así es, lo veamos como lo veamos, desde el punto de vista jurídico, un internamiento es una detención, una imposición en contra de la voluntad de una per- 
sona, que de no existir la norma que lo legitima podría subsumirse dentro el tipo de las detenciones ilegales o de las coacciones y, ad fortiori, la existencia de dicha norma no exime de cumplir escrupulosamente las normas que en nuestro ordenamiento existen para ello.

La primera y básica es la del artículo 17 de la Constitución; la segunda, derivado de éste, el artículo 520 de la Ley de enjuiciamiento criminal en cuanto a la asistencia a los detenidos. Quienes defiendan lo contrario creo que desconocen la meta, el camino o lo han olvidado. Sólo podemos prescindir de estas normas si consideramos a las personas con trastorno mental ciudadanos de segunda o pretendemos establecer algún tipo de legislación de excepción, a modo de legislación antiterrorista o similar.

Para intentar aclarar este reto debemos acudir a los orígenes del que creo debe ser nuestro camino: el tratamiento en salud mental, sus características y especialidades.

\section{De la psicocirugía a la psicofarmacología}

Como afirma Foucault (6), desde la apertura en Alemania y en Inglaterra, de las primeras casas correccionales y hasta el fin del siglo XVIII, la época clásica practica el encierro.

Se trataba de instituciones autárticas, separadas de las ciudades cuyos únicos objetivos eran contener y separar, alejar la enfermedad mental de la sociedad. La locura, sigue diciendo el citado autor, "pierde así aquella libertad imaginaria que se había desarrollado en los cielos del renacimiento: no hacía aún mucho tiempo, se debatía en pleno día, era el Rey Lear, era Don Quijote. Pero en menos de medio siglo, se encontró recluida".

En las palabras, supuestamente emitidas por el fundador en 1409 del Espital de Santa Maria de Ignoscents, folls e orats, descubrimos la finalidad de esta y otras de las instituciones creadas en Europa en los siguientes 600 años:

"En la presente ciudad hay mucha obra pía y de gran caridad y sustentación; pero aún falta una, que es de gran necesidad, cual es un "hospital" o casa donde los pobres inocentes y furiosos sean acogidos. Porque muchos pobres inocentes van por esta ciudad, los cuales pasan grandes desaires de hambre, frío e injurias. Por tal, como por su inocencia y furor no saben ganar ni pedir lo que han de menester para sustentación de su vida, por lo que duermen por las calles y perecen de hambre y de frío, muchas personas malvadas les hacen injurias y daños, y señaladamente allá donde los encuentren dormidos los vejan y matan a algunos $\mathrm{y}$ a algunas mujeres avergüenzan. 
Así mismo, los pobres hacen daño a muchas personas que van por la ciudad. Estas cosas son notorias a toda la ciudad, por lo que sería santa cosa y obra muy santa que en la ciudad de Valencia fuese hecha una habitación u "hospital" en que semejantes locos e inocentes estuviesen de tal manera que no fuesen por la ciudad ni pudiesen hacer daño ni les fuese hecho.".

En estos centros, ante la inexistencia de cualquier tratamiento, los encierros, cepos y cadenas eran frecuentes $-\mathrm{y}$ lo siguen siendo en algunas partes del mundo como se ha visto en algún documental recientemente producido (7)-.

Será a finales del XIX y principios del XX cuando comienzan a aplicarse tratamientos físicos: la infección por malaria, la terapia por shock insulínico; la terapia electroconvulsiva y, por último la leucotomia y lobotomía frontal.

En todo los casos, para su aplicación seguía siendo todavía imprescindible la institución manicomial -salvo el esperpento de las lobotomías transorbitales domiciliarias del "doctor" Walter Freeman-.

Su proliferación haría necesaria su regulación, que llegaría por primera vez a España con el Real Decreto de 12 de mayo de 1885, bajo el título de "Reglamento orgánico para el régimen y gobierno interior del manicomio de Santa Isabel de Leganés" y el Real Decreto de 19 de mayo de 1885, éste como norma ya de carácter general aplicable a todos lo "hospitales de dementes" y no sólo a aquél.

\section{El internamiento involuntario}

Estas normas instrumentalizaron un tipo de internamiento que podíamos calificar como "judicial", en tanto quedaba sometido al control del juez; sistema que perduraría hasta la siguiente norma promulgada durante la $2^{\mathrm{a}}$ República: el Decreto de 3 de julio de 1931, sobre la asistencia a los enfermos mentales.

El decreto republicano, que estaría vigente con diversas reformas hasta el año 1983 , vendría a consagrar un tipo de internamiento que podríamos calificar como de "administrativo", ya que junto con el acordado judicialmente, convivían el ordenado por el médico, por la autoridad gubernativa, jefe de policía y por el alcalde, atribuyéndose además funciones de control del ingreso al gobernador civil de la provincia.

Pero la promulgación de la Constitución en 1978 hizo necesaria la adecuación de la normativa reguladora a los principios y derechos que recogía, una norma que acogiera con todas las garantías esa situación peculiar que afectaba, entre otros derechos, a la libertad de la persona, reconocida en su artículo 17; a su libertad de residencia, artículo 18 y a la obtención de la tutela judicial efectiva, de su artículo 24 , sin que pueda producirse indefensión. 
Ello no obstante, tuvimos que esperar hasta 1983, año en el cual se produce la importante modificación llevada a cabo en el Código Civil por la Ley 13/1983 de 24 de octubre de reforma del Código Civil en materia de tutela, pasando en su artículo 211 de un sistema administrativo, a otro judicial, en el que será el Juez, como garante de la salvaguarda de la integridad de los derechos fundamentales, quien tenga la potestad exclusiva en el control del internamiento.

Pese al indudable avance en relación con la regulación anterior, buena parte de sus críticas vendrían motivadas por su ubicación, dentro de una norma de carácter material -el Código Civil- y dentro de la normativa reguladora de la incapacidad civil. La confusión estaba servida y perdurará hasta nuestros días, el internamiento pasó a estar regulado dentro de los artículos destinados a la incapacitación -artículo 211- e incluso al paciente se le denomina como "presunto incapaz" (hace poco tiempo una ex-coordinadora de la Oficina Regional de Salud Mental de Madrid, espetaba hoscamente qué cómo era posible que los pacientes internados en Foncalent no estuvieran todos incapacitados judicialmente, identificando erróneamente incapacidad con internamiento).

La citada norma se vería modificada por la LO 1/1996, de 15 de enero de Protección Jurídica del Menor en la que ya se sustituyó la anterior por la de "trastorno psíquico" e incorporando unos mecanismo de control que venían siendo exigidos por la legislación europea y la doctrina constitucional.

Dicho artículo ha estado vigente hasta el año 2000, fecha de promulgación de la Ley 1/2000 de 7 de enero de Enjuiciamiento Civil, que derogará el artículo 211 e incluirá en su articulado el artículo 763 dedicado a la materia que estudiamos.

Con la existencia de tales normas y su convalidación, primero del artículo 211 y, después, del 763, nadie dudaría de la adecuación de la norma y lo que es más grave, de su oportunidad. De hecho, miles de juristas salen cada año de la facultad con la convicción de que el único tratamiento posible para el enfermo mental es el internamiento en un hospital psiquiátrico y esto, lejos de ser resultado de un supuesto déficit intelectual o académico, se corresponde totalmente con el prejuicio social que como hemos visto acompaña desde hace siglos a la locura.

Sin embargo, ya en el año 1983 o al menos en el 96 y desde luego en el 2000, nuestra legislación al respecto debió haber girado hacía una postura más acercada a lo que ya era una palpable realidad y referirse no ya de internamiento, sino al tratamiento en salud mental.

El descubrimiento en 1952 por Henri Laborit de la clorpromazina, las propiedades antipsicóticas del haloperidol, la imipramina, el meprobamato daría origen a una disciplina enteramente nueva, la psicofarmacología, que pondría fin a los tratamientos físicos antes aludidos y, desgraciadamente, casi a la psicoterapia.

La conjunción del descubrimiento de los antipsicóticos, con los movimientos en favor de los derechos humanos y la corriente de pensamiento psiquiátrico 
ORIGINALES Y REVISIONES

denominada como "antispiquiatría", cuya principal arma sería la desinstitucionalización, daría lugar a una nueva forma de abordar el tratamiento de la enfermedad mental: la psiquiatría comunitaria y con ella el cierre de las instituciones manicomiales.

Esta clausura se iniciaría con fuerza en Italia y en Gran Bretaña, viéndose incluso sorprendentemente impulsada desde el Estado en Reino Unido y EEUU por Margaret Thatcher y Ronald Reagan, sin bien por motivos radicalmente distintos.

En España, daría comienzo mucho más tarde, en los años 80, con la creación mediante Orden de 27 de Julio de 1983 de la Comisión Ministerial para la Reforma Psiquiátrica que tendría por objeto, según su artículo $2^{\circ}$ : "Realizar los estudios necesarios para proponer los principios básicos que han de configurar la asistencia psiquiátrica de los españoles, en sus modalidades, preventiva, curativa y rehabilitadora". Está comisión publicaría en abril de 1985 un informe que serviría de base al artículo 20 de la ley 14/1986, de 25 de abril, General de Sanidad, hoy vigente:

"Sobre la base de la plena integración de las actuaciones relativas a la salud mental en el sistema sanitario general y de la total equiparación del enfermo mental a las demás personas que requieran servicios sanitarios y sociales, las Administraciones Sanitarias competentes adecuarán su actuación a los siguientes principios:

1. La atención a los problemas de salud mental de la población se realizará en el ámbito comunitario, potenciando los recursos asistenciales a nivel ambulatorio y los sistemas de hospitalización parcial y atención a domicilio, que reduzcan al máximo posible la necesidad de hospitalización.

Se considerarán de modo especial aquellos problemas referentes a la psiquiatría infantil y psicogeriatría.

2. La hospitalización de los pacientes por procesos que así lo requieran se realizará en las unidades psiquiátricas de los hospitales generales.

3 . Se desarrollarán los servicios de rehabilitación y reinserción social necesarios para una adecuada atención integral de los problemas del enfermo mental, buscando la necesaria coordinación con los servicios sociales.

4. Los servicios de salud mental y de atención psiquiátrica del sistema sanitario general cubrirán, asimismo, en coordinación con los servicios sociales, los aspectos de prevención primaria y la atención a los problemas psicosociales que acompañan a la pérdida de salud en general."

Este breve excursus histórico nos sirve para significar el cambio de paradigma en el tratamiento de la enfermedad mental: desde el encierro en la institucional asilar primero, al manicomial después, para terminar en el tratamiento en las unidades comunitarias de salud mental. Del confinamiento al internamiento y de éste, al tratamiento y sin embargo, ni nuestra legislación procesal, ni la civil han recogido ese cambio de orientación. 
Así llegamos a la tesis central de este artículo: el hecho de seguir hablando de encierros, ingresos forzosos e internamientos en salud mental, no sólo resulta peyorativo y prejuicioso, alimentando el estigma que sufren estas personas, sino que es inoperante e injusto, ya que un facultativo ni interna, ni encierra, sino que trata, interviene y por lo tanto el legislador debería aprovechar las reformas que necesariamente deberá acometer y derivadas de la exigencia que contiene la disposición adicional $7^{\text {a }}$ de la Ley 26/2011, de 1 de agosto, de adaptación normativa a la Convención Internacional sobre los Derechos de las Personas con Discapacidad necesaria adecuación a la Convención de Nueva York y, por supuesto, las derivadas de las mencionadas sentencias del Tribunal Constitucional, para sustituir en toda la legislación española, la palabra internamiento por la de tratamiento, ya que si bien el internamiento ha dejado de estar asociado al carácter correccional que se encuentra en sus orígenes, lo cierto es que la internación, no puede ser considerada, ni directa, ni indirectamente, como un tratamiento en el siglo XXI.

Sí, hagamos por un momento ese ejercicio intelectual. Sustituyamos en nuestra mente la palabra ingreso, por tratamiento. Si lo logramos, veremos cómo se desplaza la intervención en materia de salud mental, del ámbito jurídico, al ámbito puramente sanitario. Quien lo consiga, verá como se modifica el discurso y podremos dejar de hablar de abogados y procuradores, lectura de derechos, detención preventiva, habeas corpus y médicos forenses, para pasar a hablar de intervención clínica, derecho a la información, autonomía del paciente y consentimiento informado.

A mi juicio, ya no es sostenible esta legislación de excepción. Lo que comenzó como una conquista del estado de derecho, se ha convertido en una aberración, ¿realmente alguien piensa que una persona que acude o es trasladada a un hospital con un brote psicótico necesita de un abogado? Se trata de un absurdo clínico, que sin embargo desde el punto de vista jurídico y tal y como está actualmente regulado es insoslayable, siendo la argumentación del Tribunal Constitucional irreprochable.

La controversia entre los partidarios de una y otra postura, está servida. Por un lado la de aquellos para quienes la tesis expuesta rompe el sistema de garantías que tantos años ha tardado en consolidarse en nuestro país y que suprimirlo supondría abrir la puerta a posibles secuestros por móviles espurios, bajo la cobertura de un supuesto tratamiento psiquiátrico. Para otros, los que se pronunciaran en pro de mantener el statu quo, consideraran que el 763 sólo regula una situación excepcional, una situación de urgencia.

En cuanto a la primera, sinceramente creo que en las sociedades donde existe un sistema público de salud, este temor ya no se sostiene. El desarrollo del sistema sanitario, la multidisciplinariedad de los profesionales implicados, la propia diná- 
mica del estado de derecho, la libertad de prensa, la sociedad de la información, internet, el desarrollo de las redes social, hace imposible que un paciente permanezca encerrado en una institución sanitaria pública o privada, por motivos ajenos a los exclusivamente médicos y es también inconcebible que el Estado como Institución, utilice las plantas psiquiátricas de los hospitales generales como "psikhushkas" o psicoprisiones soviéticas. Sin embargo, toda la legislación civil y procesal está orientada a evitar esas desviaciones, como si el Código Penal en esta materia hubiera dejado de existir.

En cuanto a la segunda, no parece avenirse con la realidad. Efectivamente, si según la OMS (8), el mejor tratamiento para la enfermedad mental es proporcionar en el ámbito comunitario servicios de asistencia social y de salud mental completos, integrados y con capacidad de respuesta, ¿cómo es posible que una ciudad como Madrid y según la Memoria de la Fiscalía General de Estado del año 2012, se hayan tramitado en el año 2012, 21.826 expedientes de internamiento? Sesenta ingresos involuntarios diarios. ¿No será que entre todos hemos construido una estructura social, jurídica y sanitaria, que trata a los pacientes con trastorno mental grave a golpe de ingreso involuntario?

\section{La solución.}

Desde luego la deberá ofrecer nuestro legislador, que es a quien compete. Con estas líneas sólo se pretende mostrar un camino, utilizando como base las normas que al efecto existen.

La legislación material que podría sustentarlo, la encontramos en dos normas: el Convenio para la protección de los Derechos Humanos y la dignidad del ser humano con respecto a las aplicaciones de la Biología y la Medicina, hecho en Oviedo el 4 de abril de 1997 y la Ley 41/2002, de 14 de noviembre, básica reguladora de la autonomía del paciente y de derechos y obligaciones en materia de información y documentación clínica.

La adjetiva o procesal en el artículo 8 de la Ley 29/1998, de 13 de julio de jurisdicción contenciosa administrativa.

Así, en los artículos 7 y 8 de la primera de las normas mencionadas se señala que:

"Artículo 7. (Protección de las personas que sufran trastornos mentales).

La persona que sufra un trastorno mental grave sólo podrá ser sometida, sin su consentimiento, a una intervención que tenga por objeto tratar dicho trastorno, cuando la ausencia de ese tratamiento conlleve el riesgo de ser gravemente perjudicial para su salud y a reserva de las condiciones de protección previstas por 
la ley, que comprendan procedimientos de supervisión y control, así como de medios de elevación de recursos."

"Artículo 8. Situaciones de urgencia.

Cuando, debido a una situación de urgencia, no pueda obtenerse el consentimiento adecuado, podrá procederse inmediatamente a cualquier intervención indispensable desde el punto de vista médico en favor de la salud de la persona afectada".

En pleno respeto a este convenio y por necesidad inmediata de su desarrollo, se promulgo en España la denominada Ley de Autonomía del Paciente, en cuyo articulado y tras exponer en su artículo 2, bajo la rúbrica de "principios básicos" que:

"Toda actuación en el ámbito de la sanidad requiere, con carácter general, el previo consentimiento de los pacientes o usuarios. El consentimiento, que debe obtenerse después de que el paciente reciba una información adecuada, se hará por escrito en los supuestos previstos en la Ley".

También se afirma en su artículo 9, bajo la rúbrica de "Límites del consentimiento informado y consentimiento por representación", que:

"2. Los facultativos podrán llevar a cabo las intervenciones clínicas indispensables en favor de la salud del paciente, sin necesidad de contar con su consentimiento, en los siguientes casos:

a) Cuando existe riesgo para la salud pública a causa de razones sanitarias establecidas por la Ley. En todo caso, una vez adoptadas las medidas pertinentes, de conformidad con lo establecido en la Ley Orgánica 3/1986, se comunicarán a la autoridad judicial en el plazo máximo de 24 horas siempre que dispongan el internamiento obligatorio de personas.

b) Cuando existe riesgo inmediato grave para la integridad física o psíquica del enfermo y no es posible conseguir su autorización, consultando, cuando las circunstancias lo permitan, a sus familiares o a las personas vinculadas de hecho a él".

Se trata como vemos de dos supuestos; el primero como actuación general de salud pública, regulado por la citada ley orgánica, en cuyo artículo 2 se establece que:

"Las autoridades sanitarias competentes podrán adoptar medidas de reconocimiento, tratamiento, hospitalización o control cuando se aprecien indicios racionales que permitan suponer la existencia de peligro para la salud de la población debido a la situación sanitaria concreta de una persona o grupo de personas o por las condiciones sanitarias en que se desarrolle una actividad".

El segundo, por razones de urgencia o riesgo grave para la salud física o psíquica del interno. 
La normativa procesal se encuentra en el artículo 8 de la Ley 29/1998, de 13 de julio de jurisdicción contenciosa administrativa, en donde se recoge que a los Juzgados de lo Contencioso Administrativo les corresponderá "la autorización o ratificación judicial de las medidas que las autoridades sanitarias consideren urgentes y necesarias para la salud pública e impliquen privación o restricción de la libertad o de otro derecho fundamental".

Es cierto que está pensado para la aplicación de la Ley Orgánica 3/1986, pero también lo es que no conozco ningún artículo en el Código Civil cuya aplicación exija en esta materia la intervención de los Juzgados de $1^{\mathrm{a}}$ Instancia y, por lo tanto, de desarrollo por la Ley de Enjuiciamiento Civil. Esto supondría abrogar de facto el artículo 763 y con él, la competencia de los juzgados de $1^{\mathrm{a}}$ Instancia, salvo que el paciente tuviera su capacidad revisada y se hubiera nombrado como figura de apoyo, un tutor o un curador en el ámbito de su salud, ya que en este caso sería imprescindible la supervisión por el juez que controla la tutela.

Toda esta normativa forma un corpus legis que debería informar la futura reforma legislativa, que podría fundamentarse en alguno de los siguientes principios:

Primero: Pleno respeto al derecho a la información asistencial previsto en el artículo 5 de la Ley 41/2002.

Segundo: Consentimiento informado, que en caso de tratamiento psiquiátrico deberá siempre hacerse constar por escrito, por lo que así habrá de hacerse mención expresa en el artículo 8 de la Ley 41/2002.

Tercero: El ejercicio de estos derechos se manifestará en la existencia de un plan de tratamiento, cuyos objetivos, medidas y ayudas que compone deberán constar por escrito.

Cuarto: Este plan de tratamiento deberá cumplir las siguientes premisas:

- Ser universal y gratuito, fundamentado en prácticas probadamente eficaces, basadas en evidencias.

- El paciente será parte activa en su diseño, implementación y desarrollo.

- Formará parte de su historia clínica.

- Deberá tener un enfoque integral y multisectorial, con coordinación de los servicios sanitarios y sociales y posibles alianzas con sectores públicos y privados.

- Además de las medidas farmacológicas, sociales y psicológicas que se consideren oportunas, se hará constar por pare del interesado la designación de las personas a las que también legitima para recibir dicha información clínica.

- Asimismo, el interesado podrá designar a una persona física o jurídica como "agente facilitador" o "agente comunitario" o "persona o grupo de apoyo". Da igual su denominación, se trata de alguien a quien el propio paciente designa como referente personal y a quien las autoridades sanitarias y sociales 
deberán acudir ante una crisis psiquiátrica o una perdida transitoria de la capacidad para consentir.

- Deberá describir las medidas previstas para su control, continuación y seguimiento.

Quinto: Deberá dictarse una norma reglamentaria en la que se desarrollen detalladamente las "Instrucciones previas" en el ámbito psiquiátrico -denominadas coloquialmente como "contrato de Ulises"-, regulado de forma básica en el artículo 11 de la Ley 41/2002, que de existir se hará constancia expresa en su historia clínica.

Sexto: Ante la existencia de una situación de urgencia en la que se encuentre en riesgo la salud del paciente, el psiquiatra podrá acordar su traslado para tratamiento forzoso a un hospital general.

La situación permanecerá hasta que el paciente recupere su capacidad para consentir, momento en el cual se reanudará o pactará un nuevo plan de tratamiento.

Séptimo: El incumplimiento del nuevo plan de tratamiento legitimará al equipo sanitario que le atienda para adoptar las decisiones que se consideren oportunas, de lo que se dará cuenta, para su supervisión, al juzgado del partido judicial donde radique el centro sanitario.

Octavo: El incumplimiento reiterado del plan de tratamiento o la manifiesta falta de competencia del paciente para el cuidado de su salud, será comunicado al Ministerio Fiscal para la incoación de un procedimiento de revisión de la capacidad, con la finalidad de designar a una persona de apoyo que supervise el cumplimiento del tratamiento pautado, dando cuenta al juzgado.

Existirán otros muchos principios y sin duda voces mucho más autorizadas para su exposición y desarrollo. Lo importante es no dejar de nuevo pasar la oportunidad y que pasados los años sigamos refiriéndonos a ingresos e internamientos forzosos en el ámbito de la salud mental.

\section{BIBLIOGRAFÍA}

(1) Boletín Oficial de las Cortes Generales. Congreso de los Diputados Núm. B-101-1 de 19/07/2004 P. 1. Proposición de Ley de modificación de la Ley de Enjuiciamiento Civil para regular los tratamientos no voluntarios de las personas con trastornos psíquicos (122/000085). Presentado el 06/07/2004, calificado el 13/07/2004.

(2) Documento AEN sobre la propuesta de regulación del tratamiento ambulatorio involuntario; aprobado por la Junta Directiva de la Asociación Española de Neuropsiquiatría en su reunión de fecha 28 - 29 de enero de 2005 en Madrid. Consultado 05-07-2013). Disponible en: http://aen.es/ docs/TAI05.pdf 
ORIGINALES Y REVISIONES

(3) Naciones Unidas - Asamblea General. Informe del Relator Especial sobre la tortura y otros tratos o penas crueles, inhumanos o degradantes, Juan E. Méndez. A/HRC/22/53 1 de febrero de 2013. Disponible en http://www.ohchr.org/Documents/HRBodies/HRCouncil/RegularSession/ Session22/A-HRC-22-53_sp.pdf

(4) Boletín Oficial del Estado de 5 de Enero de 2011.

(5) Boletín Oficial del Estado de 30 de julio de 2012.

(6) Foucault M. Historia de la locura en la época clásica. 10ª ed. México FCE: Editorial Fondo de cultura económica, 2006.

(7) Los olvidados de los olvidados". Documental coproducido en 2010 por TVE, Chello Multicanal (Odisea) y Aigua Films con guión y dirección de Carles Caparrós.

(8) Organización Mundial de la Salud. Proyecto de plan de acción integral sobre salud mental 2013-2020 (eb132/8; Consejo ejecutivo $132{ }^{a}$ reunión, 11 de enero d 2013. 